\title{
MiR-22 may Suppress Fibrogenesis by Targeting TGF $\beta R$ I in Cardiac Fibroblasts
}

\author{
Yuan Hong ${ }^{a}$ Huaming Cao ${ }^{b}$ Qiang Wang ${ }^{b}$ Jianlin Ye ${ }^{a}$ Lijun Suic Jinhua Feng ${ }^{d}$ \\ Xiaojun Cai ${ }^{\mathrm{e}}$ Huizhu Song ${ }^{\mathrm{e}}$ Xiuhong Zhang ${ }^{\mathrm{e}}$ Xichuang Chen $^{\mathrm{d}}$ \\ aDepartment of Pharmacy, Affiliated Wuxi Children's Hospital, Nanjing Medical University, Wuxi, \\ bDepartment of Internal Medicine, 'Department of Pharmacy, Affiliated Wuxi People's Hospital, Nanjing \\ Medical University, Wuxi, 'Department of Internal Medicine, 'Department of Pharmacy, Affiliated Wuxi \\ No.9 People's Hospital, Soochow University \& Wuxi Hand Surgery Hospital, Wuxi, China
}

\section{Key Words}

Myocardial infarction $•$ Cardiac fibrosis $•$ MicroRNA-22 - TGFßRI

\begin{abstract}
Background/Aims: Cardiac fibrosis after myocardial infarction (MI) has been identified as a key factor in the development of heart failure, but the mechanisms undelying cardiac fibrosis remained unknown. microRNAs (miRNAs) are novel mechanisms leading to fibrotic diseases, including cardiac fibrosis. Previous studies revealed that miR-22 might be a potential target. However, the roles and mechanisms of miR-22 in cardiac fibrosis remained ill defined. The present study thus addressed the impact of miR-22 in cardiac fibrosis. Methods: After seven days following coronary artery occlusion in mice, tissues used for histology were collected and processed for Masson's Trichrome staining. In addition, cardiac fibroblasts were transfected with mimics and inhibitors of miR-22 using Lipofectamin 2000, and luciferase activity was measured in cell lysates using a luciferase assay kit. Western blotting was used to detect the expression of collagen $1, \alpha-S M A$ and TGF $\beta$ RI proteins levels, and real time-PCR was employed to measure the Coll $\alpha 1$, Col3 $\alpha 1$, miR-22 and TGF $\beta R I$ mRNA levels. Results: In this study, we found that miR-22 was dynamically downregulated following MI induced by permanent ligation of the left anterior descending coronary artery for 7 days, an effect paralleled by significant collagen deposition. Inhibition of miR-22 with AMO-22 resulted in increased expression of Col $1 \alpha 1$, Col $3 \alpha 1$ and fibrogenesis in cultured cardiac fibroblasts. Conversely, overexpression of miR-22 in cultured cardiac fibroblasts significantly abrogated angiotensin II-induced collagen formation and fibrogenesis. Furthermore, we found that TGF $\beta R I$ is a direct target for miR-22, and downregulation of TGF $\beta R$ may have mediated the antifibrotic effect of miR-22. Conclusion: Our data clearly demonstrate that miR-22 acts as a novel negative regulator of angiotensin II-induced cardiac fibrosis by suppressing the expression of TGF $\beta R I$ in the heart and may represent a new potential therapeutic target for treating cardiac fibrosis.
\end{abstract}

Y. Hong and H. Cao contributed equally to this work.

Xichuang Chen

KARGER
Department of Pharmacy, Affiliated Wuxi No.9 People's Hospital, Soochow University and Wuxi Hand Surgery Hospital, Liangxi Road 999, Wuxi, Jiangsu 214062, (China) Tel. and Fax +86-510-85807001, E-Mail cxcyilanxs@aliyun.com 


\section{Cellular Physiology Cell Physiol Biochem 2016;40:1345-1353

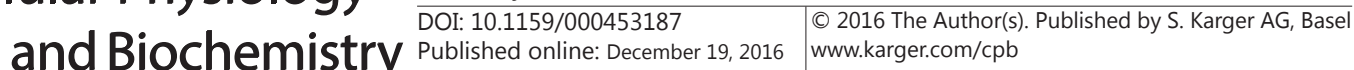 \\ Hong et al.: MiR-22 Suppress Cardiac Fibrogenesis by Targeting TGF $\beta$ RI}

\section{Introduction}

Cardiac ischaemia leading to post-infarction heart failure particularly in patients with large myocardial infarction is associated with a high mortality. Excessive fibrosis leads to ventricular dilation, infarct expansion, and heart failure [1]. During cardiac remodeling, fibroblasts differentiate into myofibroblasts. These are fast-proliferating, $\alpha$-smooth muscle cell actin $(\alpha-S M A)$-positive cells with pronounced contractile and secretory properties [2]. Myofibroblasts can be induced by transforming growth factor (TGF)- $\beta$ and lead to excessive matrix accumulation [3]. Therefore, elucidating the molecular mechanism of cardiac fibrosis is of great value for the clinical therapy of it. MicroRNAs (miRNAs) are small non-coding RNAs that regulate gene expression at the post-transcriptional level by either degradation or translational repression of a target mRNA [4]. Lots of studies have showed that miRNAs are involved in the process of kinds of diseases, especially in various fibrotic diseases, including cardiac fibrosis, idiopathic pulmonary fibrosis, liver fibrosis, and so on [5-7]. In the previous study, van Rooij et al. found that miR-22 was decreased in the border zone region of mice both 3 days and 14 days after MI [8]. And, a study from Guo et al. showed that miR-22 inhibited cell proliferation, migration, and invasion of osteosarcoma cells [9]. However, the role and mechanisms of miR-22 on cell proliferation of cardiac fibroblasts and myocardial fibrosis is largely unknown.

In this study, we found that miR-22 was down-regulated in the mice of experimental cardiac fibrosis induced by myocardial infarction. And, inhibition of miR-22 caused fibrogenesis in cultured cardiac fibroblasts, whereas over-expression of miR-22 attenuated Ang II-induced collagen content enhancement in vitro. Furthermore, our data showed that miR-22 is involved in the process of cardiac fibrosis by regulation of TGF $\beta$ RI. These results indicate that miR-22 is a novel therapeutic target for myocardial fibrosis.

\section{Materials and Methods}

\section{Surgical Procedures}

All animal protocols were approved by the Institutional Animal Care. Adult C57BL/6 male mice were anesthetized with $2.4 \%$ isoflurane and placed in a supine position on a heating pad $\left(37^{\circ} \mathrm{C}\right)$. Animals were intubated with a 19G stump needle and ventilated with room air, using a MiniVent mouse ventilator (Hugo Sachs Elektronik; stroke volume, 250 ul; respiratory rate, 210 breaths per minute). Via left thoracotomy between the fourth and fifth ribs, the left anterior coronary artery (LCA) was visualized under a microscope and ligated by using a 6-0 prolene suture. Regional ischemia was confirmed by visual inspection under a dissecting microscope (Leica) by discoloration of the occluded distal myocardium. Sham operated animals underwent the same procedure without occlusion of the LCA.

Masson's trichrome staining

Tissues used for histology were incubated in Krebs-Henselheit solution, fixed in 4\% paraformaldehyde, sectioned, and processed for Masson's Trichrome staining [10].

\section{Cell culture and treatment}

Cardiac fibroblasts (CFs) were isolated as previous described [3]. Briefly, hearts were excised from anesthetized neonatal 1 to 2-day-old Sprague-Dawley rats (Harlan Sprague-Dawley), minced, and digested with pancreatin $0.1 \%$. Cells were plated on primaria plates for $2 \mathrm{~h}$, and the medium that contained the cardiomyocyte fraction of the digested tissue was removed. Cardiac fibroblasts attached and proliferated much more rapidly than cardiac myocytes; this produced virtually pure fibroblast cultures after the first passage, which was confirmed by repeated differential plating and microscopic evaluation. Cells were detached with $0.05 \%$ trypsin for passaging, and culture studies were performed at passages 2 to 4 . Cells were grown in high glucose (4.5 gm/lt) DMEM containing $10 \%$ heat-inactivated FBS and antibiotics (penicillin and streptomycin).

\section{KARGER}




\section{Cellular Physiology Cell Physiol Biochem 2016;40:1345-1353 \begin{tabular}{l|l} 
and BiOChemistry Published online: December 19, 2016 & $\begin{array}{l}\text { (c) } 2016 \text { The Author(s). Published by S. Karger AG, Basel } \\
\text { www.karger.com/cpb }\end{array}$
\end{tabular} \\ Hong et al.: MiR-22 Suppress Cardiac Fibrogenesis by Targeting TGF $\beta$ RI}

Transfection procedure

Rat cardiac fibroblasts were transfected with mimics and inhibitors of miR-22 (100 nM, Sangon, Shanghai, China) using Lipofectamin 2000 (Invitrogen, Carlsbad, CA).

Real time-PCR

After experimental treatment, total RNA samples were isolated from cardiac tissues and cultured cardiac fibroblasts using Trizol reagent (Invitrogen, CA, USA) according to manufacturer's protocol. RNA was then reverse transcribed using High-Capacity cDNA Reverse Transcription Kit (Applied Biosystems, CA, USA) to obtain first-strand cDNA. Levels of Col1 $\alpha 1$, Col3 $\alpha 1$, miR-22 and TGFßRI mRNA were determined using SYBR Green I incorporation methods on ABI 7500 fast Real Time PCR system (Applied Biosystems), with U6 as an internal control of miRNA or GAPDH as an internal control of mRNA.

\section{Western blotting}

Protein lysates were prepared as described [11]. We used primary antibodies against TGFßRI, collagen1, $\alpha$-SMA, GAPDH (Santa Cruz, CA), as well as appropriate secondary antibodies.

\section{Luciferase assays}

HEK293 cells were transfected with $0.1 \mathrm{mg}$ p-MIR-report plasmid (Ambion) containing the 3'-UTR of rat TGFBRI RNA and $50 \mathrm{nM}$ of miR-22 using Lipofectamine 2000 (Invitrogen). Forty-eight hours later luciferase activity was measured in cell lysates using a luciferase assay kit (Promega).

\section{Statistical assays}

Average data are presented as mean \pm SEM. Statistical analysis was carried out using the Prism software (GraphPad). For statistical comparison of two groups, we used unpaired, two-tailed Student's t-test; for the comparison of three or more groups, we used ANOVA followed by Fisher's post-test. Differences were considered significant when $p<0.05$.

\section{Results}

miR-22 is decreased in mice after myocardial infarction (MI)

In an effort to identify the role of miR-22 in post-MI remodeling, we first constructed MI by occlusion of the left coronary artery (LCA). After seven days, Masson staining showed that there are markedly collagen deposition in MI mice compared sham group (Fig. 1A). And, real-time PCR assay found that the mRNA levels of Col1 $\alpha 1$, Col3 $\alpha 1$ were significantly increased in MI mice (Fig. 1B \& 1C). Furthermore, Western blot showed that the expression of collagen 1 and $\alpha$-SMA were significantly up-regulated in the MI mice than that in sham mice (Fig. 1D). At the same time, real-time PCR found that miR-22 was decreased in the border zone of the infarction region compared with that of the sham-operated mouse hearts (Fig. 1E), indicating that miR-22 may participates in the process of post-MI remodeling.

\section{Inhibition of miR-22 increased the production of collagen in cardiac fibroblasts}

To investigate whether miR-22 plays important roles in the process of cardiac fibrosis, we administrated AMO-22, the antisense oligonucleotide of miR-22, into cultured cardiac fibroblasts and evaluated the fibrogenesis of these cells. As illustrated in Fig. 2A, AMO22 inhibited the endogenous expression of miR-22. And, inhibition of miR-22 caused significantly increased of Col $1 \alpha 1$ and Col3 $\alpha 1$ at mRNA levels (Fig. 2B \& 2C). Furthermore, using western blot assay, we found that the expression of collagen 1 and $\alpha$-SMA were elevated in the cultured cardiac fibroblasts after transfection of AMO-22 (Fig. 2D).

Overexpression of miR-22 alleviated Ang II-induced collagen content

To determine whether overexpression of miR-22 was capable of reducing collagen expression, we exposed fibroblasts to a miR-22 mimic. As shown in Fig. 3A, the level of miR22 expression in cultured fibrobalsts was increased by as much as 100 -fold after transfection 


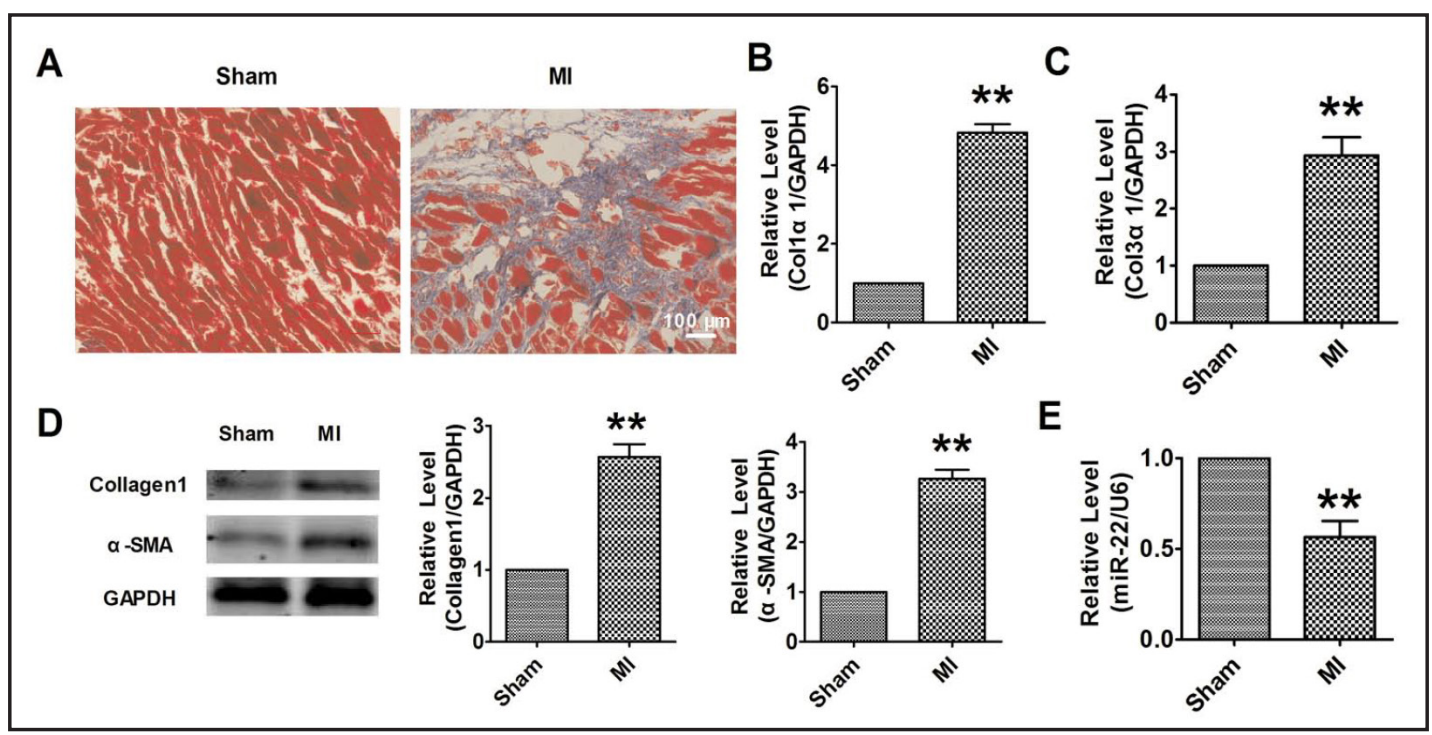

Fig. 1. miR-22 is down-regulated in the border zone of the infarcted region after MI. (A) Masson Trichrome staining of mouse heart sections shows collagen deposition and interstitial fibrosis in the border zone of the infarcted region 7 days after MI. Bothe the mRNA levels of Col1 $\alpha 1$ (B) and Col3 $\alpha 1$ (C) were up-regulated in the MI mice compared with sham group. (D) Western blot assays showed the increased collagen 1 and $\alpha$-SMA expression in the heart of with MI. (E) Real-time PCR analysis confirms the decreased miR-22 in response to MI compared with sham operated animals. $\mathrm{n}=3^{* *} p<0.01$ vs. sham group.

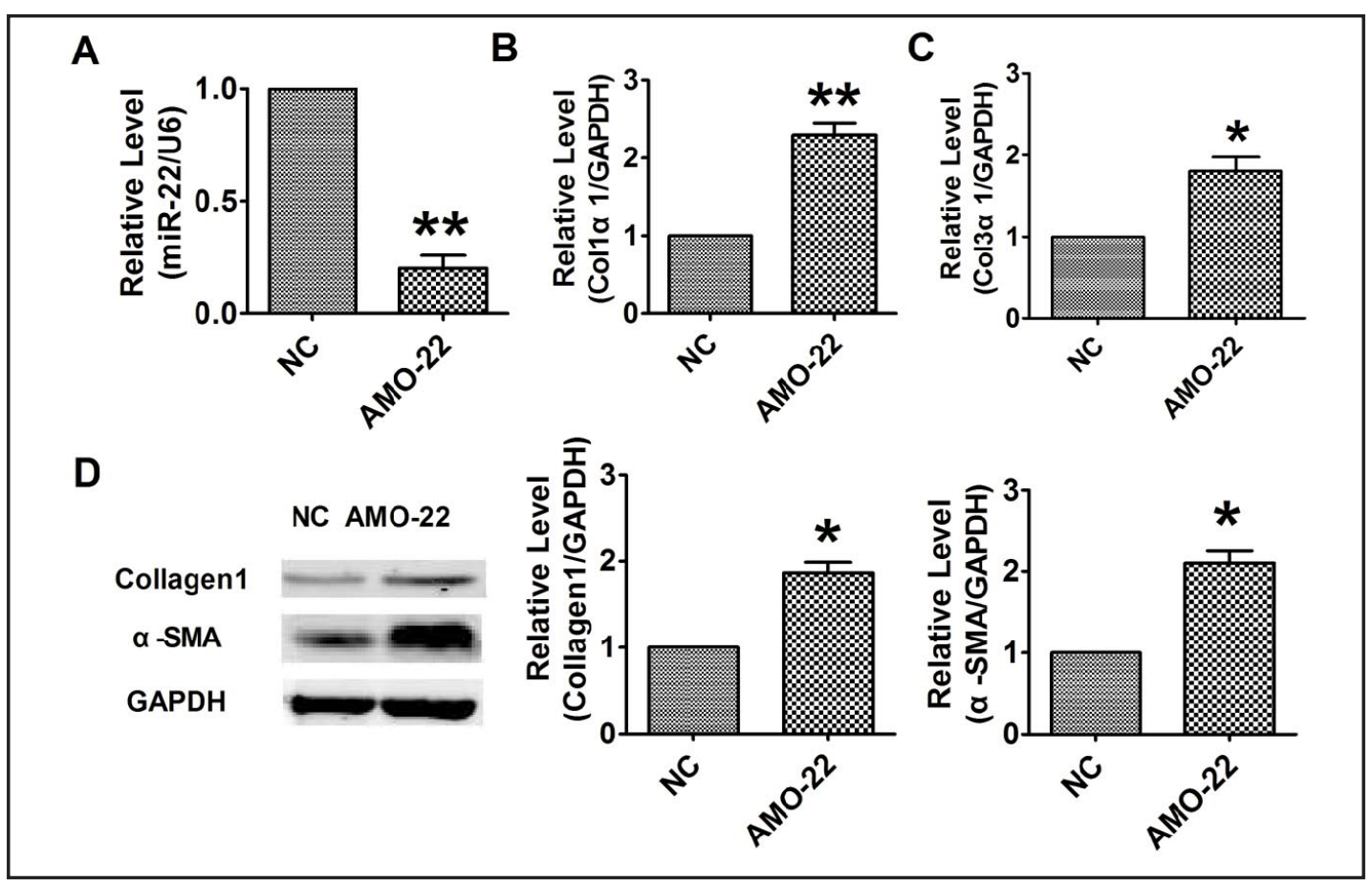

Fig. 2. In vitro silencing silencing of miR-22 caused fibrogenesis in cultured cardiac fibroblasts. (A) Real-time PCR analysis the inhibition of miR-22 after transfection of AMO-22 in cultured cardiac fibroblasts. Inhibition of miR-22 induced up-regulation of Col1 $\alpha 1$ (B) and Col3 $\alpha 1$ (C) at mRNA level. (D) Silencing of miR-22 increased collagen 1 and $\alpha$-SMA expression at protein level in cultured cardiac fibroblasts. $\mathrm{n}=3{ }^{*} p$ $<0.05, * * p<0.01$ vs. NC group.

of miR-22. And, real-time PCR analysis indicated that forced expression of miR-22 diminished the up-regulated Col $1 \alpha 1$ and Col3 $\alpha 1$ caused by Ang II in cultured cardiac fibroblasts (Fig. 3B 


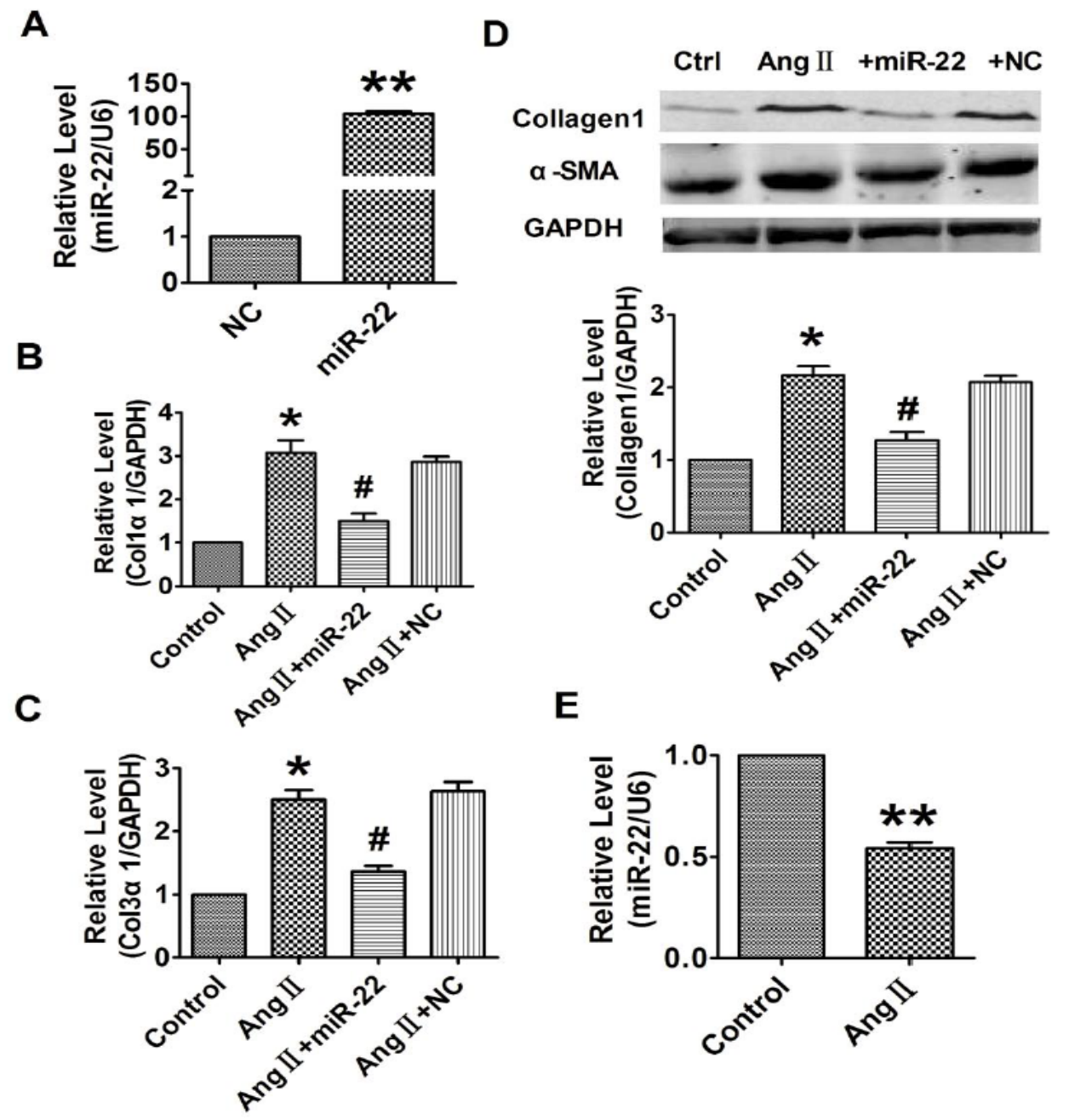

Fig. 3. Forced expression of miR-22 attenuated Ang II-induced fibrogenesis in cultured cardiac fibroblasts. (A) Transfection of miR-22 enhanced the expression of miR-22 in cardiac fibroblasts. Overexpression of miR-22 abrogated increased Col $1 \alpha 1$ (B) and Col3 $\alpha 1$ (C) caused by Ang II. (D) Forced expression of miR-22 attenuated Ang II-induced up-regulation of collagen 1 and $\alpha$-SMA expression at protein level in cultured cardiac fibroblasts. (E) Show Ang II-induced on the expression of miR-22 in fibroblasts. $\mathrm{n}=3{ }^{*} p<0.05$, ** $p<0.01$ vs. NC or Control group. \#p $<0.05$ vs. Ang II.

\& 3C). At the same time, miR-22 alleviated the Ang II-induced alteration of fibrotic-related proteins, including collagen 1 and $\alpha$-SMA (Fig. 3D). The Ang II-induced on the expression of miR-22 in fibroblasts (Fig. 3E).

\section{TGFBRI mediated the anti-fibrotic effect of miR-22}

To exploit the underlying mechanism of miR-22 in myocardial fibrosis, we performed miRNA gene target prediction using Target-Scan 6.0 database, and we indeed identified a binding site in the 3'-UTR of TGF $\beta$ RI mRNA for miR-22, which is highly conserved among human, rat and mouse (Fig. 4A). At the same time, TGF $\beta$ RI was also increased in the heart of mice after occlusion of LCA (Fig. 4B), these results suggest a targeting relationship between miR-22 and TGF $\beta R I$. We then experimentally verified the regulation of TGF $\beta$ RI by miR-22 with luciferase activity assay in HEK-293 cells. And, luciferase assay showed that miR-22 significantly inhibited luciferase activity elicited by the pMIR-REPORTTM luciferase vector containing the target sequence (Fig. 4C). Furthermore, our following data confirmed that 


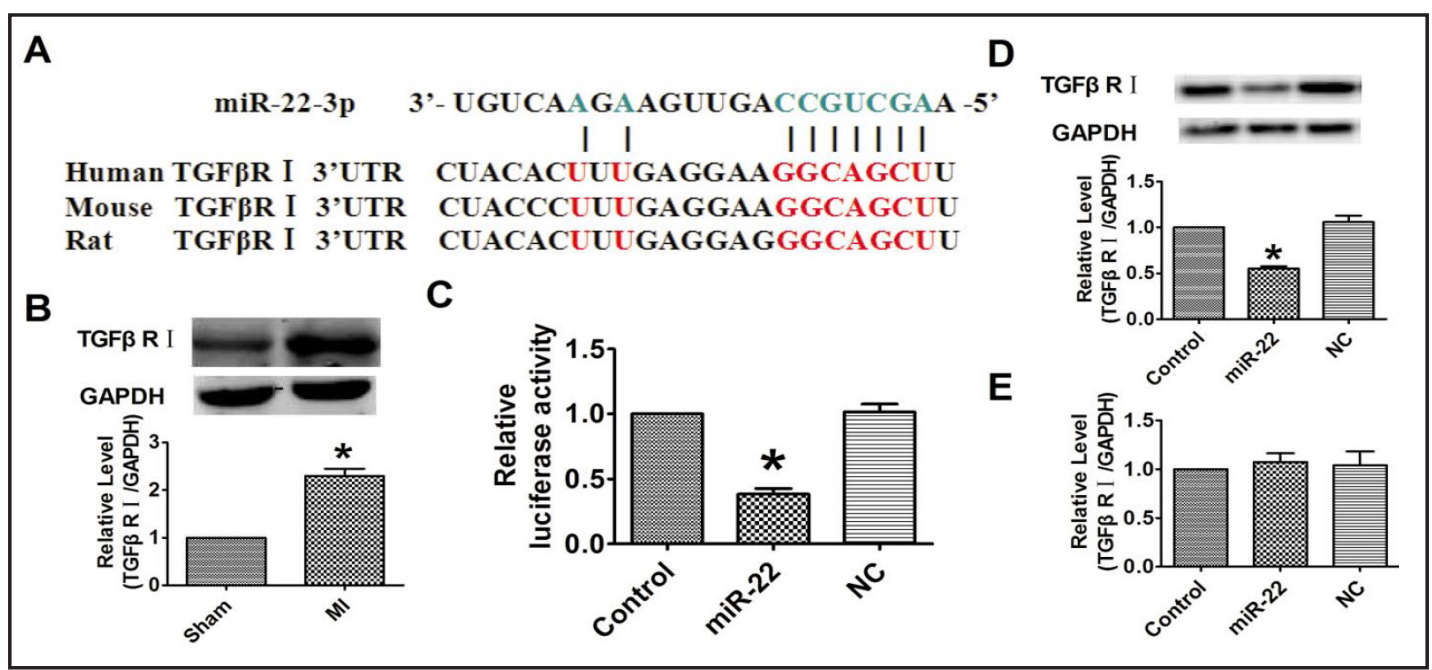

Fig. 4. TGF $\beta R I$ is a direct target for miR-22. (A) The predicted duplex of miR-22 and its targets sites in the 3'-untranslated region (3'-UTR) of TGF 3 RI. (B) Western blot analysis the alteration of TGF $\beta R I$ in the mice after MI. (C) Dual luciferase assay was performed in HEK293 cells transfection of luciferase reporter construct alone or cotransfected with miR-22 or NC. Firefly luciferase activity was normalized to Renilla luciferase activity for each sample. (D) Western blot was performed to verify the effect of miR-22 on TGF $\beta$ RI at protein level. (E) Real time PCR analysis the effect of miR-22 on TGFßRI at mRNA level. $\mathrm{n}=3 ;{ }^{*} p<0.05 v s$. Sham or NC group.

miR-22 inhibited the expression of TGF $\beta R I$ at protein level (Fig. 4D), whereas has no effect on its mRNA level (Fig. 4E). These results indicated that miR-22 regulate TGF $\beta R I$ in a posttranscriptionally manner.

\section{Discussion}

The data presented here show that miR-22 participate in the pathogenesis of myocardial fibrosis. Our data found that miR-22 is decreased in the mice after MI, which along with increase of collagen deposition. And, inhibition of miR-22 caused fibrogenesis in cultured cardiac fibroblasts. Furthermore, forced expression of miR-22 abrogated the Ang II-induced elevated the production of collagen. Meanwhile, we found that TGFßRI is one of the targets for miR-22. These findings indicate that miR-22 is an important mediator for cardiac fibrosis and suggest that miR-22 may be a novel target in treating myocardial fibrosis.

More and more studies have provided strong evidence that miRNAs play important roles in the process of cardiac fibrosis [4]. van Rooij et al. found that miR-29 family, including miR-29a, miR-29b and miR-29c were downregulated in the region of the heart adjacent to the infarct. And, over-expression of miR-29 in fibroblasts reduces collagen expression by targeting a cadre of mRNA that encodes proteins involved in fibrosis [8, 12-14]. Zhao et al. illustrated that miR-101a exerts anti-fibrotic effects by targeting TGF $\beta$ RI, suggesting that miR-101a plays a multi-faceted role in modulating TGF $\beta$ signaling pathway and cardiac fibrosis [15]. Yin et al. found that low ambient temperature could cause enlarged heart, ultrastructure damage of myocardium and weakened functions, and Resveratrol treatment could inhibit the increase of miR-328 and effectively suppress these changes at least partially via inhibiting cardiomyocyte apoptosis [16]. MiR-21 is another master regulator of cardiac fibrosis [17-19]. Thum et al. found that miR-21 induces cardiac fibrosis by targeting sprouty homologue 1 (Spry1), and silencing of miR-21 inhibits pressure-overload-induced interstitial fibrosis and attenuates cardiac dysfunction in mouse [20]. In addition, others researchers also 
confirmed that miR-21 contributes to the pathological process of cardiac fibrosis [1, 7]. Rudy F. Duisters and colleagues found that miR-133 and miR-30 was decreased in pathological left ventricular hypertrophy and contributes to collagen synthesis. And, overexpression of these two miRNAs decreased CTGF, which was accompanied by decreased production of collagens [21]. However, the role and underlying molecular mechanism of miRNAs in cardiac fibrosis remains unclear.

Increasing evidence showed that miR-22 participated in kinds of disease, such as cancer, diabetes [22], and cardiovascular diseases [23]. Anmad et al. report that miR-22 is downregulated in peripheral blood mononuclear cells derived from chronic myeloid leukemia (CML) patients and in CML cell line K562 [24]. And, overexpression of miR-22 inhibits proliferation and alteration in cell cycle of K562 cells by regulating neuro-epithelial transforming gene 1 (NET1). A study from Kaur et al. showed that in vivo silencing of miR-22$3 p$ by antagomiR administration lowered random as well as fasting glucose levels in diabetic mice. MiR-22-3p antagonism improved glucose tolerance and insulin sensitivity [22].

MiR-22 is an evolutionally conserved miRNA that is highly expressed in the heart. Extensive studies have demonstrated that miR-22 contributes to cardiac hypertrophy through modulates the expression and function of genes involved in hypertrophic response, sarcomere reorganization, and metabolic program shift during cardiac remodeling [23]. Huang et al. found that miR-22 regulates cardiac hypertrophy, and miR-22 deficient mice are unable to properly develop cardiac hypertrophy in response to isoproterenol administration [25]. In addition, another study from Gurha et al. showed that miR-22 is a regulator of $\mathrm{Ca}^{2+}$ homeostasis in the heart, and deletion of miR-22 in the heart promotes stress-induced cardiac dilation and contractile dysfunction [26]. At the same time, Gurha P and colleagues found that miR-22 promotes heart failure through post-transcriptionally inhibits peroxisome proliferator-activated receptor gamma coactivator 1 alpha (PGC-1 $\alpha$ ), PPAR $\alpha$ and sirtuin 1 (SIRT1) expression [27]. In the previous study, we found that miR-22 is downregulated in the MI mice from the microarray data of van Rooij [8]. However, whether miR-22 involved in the process of cardiac fibrosis is still unknown. The present study found that miR-22 is decreased in the heart of mice after MI, and overexpression of miR-22 inhibits Ang II-induced fibrogenesis in cultured cardiac fibroblasts. These results highlight the potential anti-fibrotic function of miR-22 in the treatment for the cardiac remodeling after MI. However, further studies will be necessary to explain the functional and mechanisms of miR-22 in vivo.

Normal tissue repair requires the produced new connective tissue, which is performed by myofibroblasts, a specific cell type expresses the pro-contractile protein $\alpha$-smooth muscle actin $(\alpha-S M A)$ [28]. However, inappropriately terminated tissue repair program and excessive deposition of scar tissue and extracellular matrix (ECM) result in chronic fibrotic diseases, which affect some organs such as heart, lung and liver, and finally lead to organ failure and resulting in death $[29,30]$. As is well known, transforming growth factor $\beta 1$ (TGF- $\beta 1$ ) is a major contributor to fibrotic diseases, including cardiac fibrosis. Active TGF- $\beta 1$ binds to a complex of TGF $\beta$ type I and TGF $\beta$ type II receptors, resulting in the phosphorylation of the receptor-activated Smads (R-Smads), Smad2 and 3, by the TGF $\beta$ receptor I kinase. Activated Smad2/3 binds Smad4 and become localized into the nucleus where they can activate transcription [28]. Previous studies have demonstrated that inhibiting TGFßRI with a TGF $\beta$ RI inhibitor significantly attenuated left ventricular remodeling and improved systolic dysfunction in rat MI models [31]. In our study, we report that TGF $\beta R I$ is a novel target of miR-22, and mediated the anti-fibrotic effect of miR-22 in cultured cardiac fibroblasts.

In summary, this study examined the alteration and the function of miR-22 on the progression of post-infarction left ventricular (LV) remodeling in mice. Our results showed that miR-22 expression was reduced in the heart of mice after MI. And forced expression of miR-22 in cultured cardiac fibroblasts attenuated Ang II-induced fibrogenesis by targeting TGF $\beta$ RI. Additional studies will be needed to evaluate the potential role of miR- 22 as a therapeutic strategy for cardiac fibrosis. 


\section{Cellular Physiology Cell Physiol Biochem 2016;40:1345-1353 \begin{tabular}{cc|c|c|} 
DOI: 10.1159/000453187 & $\begin{array}{l}\text { O } 2016 \text { The Author(s). Published by S. Karger AG, Basel } \\
\text { wwww.karger.com/cpb }\end{array}$
\end{tabular}}

Hong et al.: MiR-22 Suppress Cardiac Fibrogenesis by Targeting TGF $\beta$ RI

\section{Acknowledgments}

This work was supported by grants from Wuxi Municipal Science and Technology Bureau [CSZ0N1405 and CSZ0N1624] and Pharmaceutical Foundation of the Management Center of Wuxi Hospital [YGZXY1314].

\section{Disclosure Statement}

We declare no competing interests.

\section{References}

1 Roy S, Khanna S, Hussain SR, Biswas S, Azad A, Rink C, Gnyawali S, Shilo S, Nuovo GJ, Sen CK: MicroRNA expression in response to murine myocardial infarction: miR-21 regulates fibroblast metalloprotease-2 via phosphatase and tensin homologue. Cardiovasc Res 2009;82:21-29.

2 Melchior-Becker A, Dai G, Ding Z, Schafer L, Schrader J, Young MF, Fischer JW: Deficiency of biglycan causes cardiac fibroblasts to differentiate into a myofibroblast phenotype. J Biol Chem 2011;286:17365-17375.

3 Tillmanns J, Hoffmann D, Habbaba Y, Schmitto JD, Sedding D, Fraccarollo D, Galuppo P, Bauersachs J: Fibroblast activation protein alpha expression identifies activated fibroblasts after myocardial infarction. J Mol Cell Cardiol 2015;87:194-203.

4 Thum T: Noncoding RNAs and myocardial fibrosis. Nat Rev Cardiol 2014;11:655-663.

5 Yang JJ, Tao H, Deng ZY, Lu C, Li J: Non-coding RNA-mediated epigenetic regulation of liver fibrosis. Metabolism 2015;64:1386-1394.

6 Pandit KV, Milosevic J: MicroRNA regulatory networks in idiopathic pulmonary fibrosis. Biochem Cell Biol 2015;93:129-137.

7 Liang H, Zhang C, Ban T, Liu Y, Mei L, Piao X, Zhao D, Lu Y, Chu W, Yang B: A novel reciprocal loop between microRNA-21 and TGFßR III is involved in cardiac fibrosis. Int J Biochem Cell Biol 2012;44:2152-2160.

8 van Rooij E, Sutherland LB, Thatcher JE, DiMaio JM, Naseem RH, Marshall WS, Hill JA, Olson EN: Dysregulation of microRNAs after myocardial infarction reveals a role of miR-29 in cardiac fibrosis. Proc Natl Acad Sci USA 2008;105:13027-13032.

9 Guo S, Bai R, Liu W, Zhao A, Zhao Z, Wang Y, Zhao W, Wang W: miR-22 inhibits osteosarcoma cell proliferation and migration by targeting HMGB1 and inhibiting HMGB1-mediated autophagy. Tumour Biol 2014;35:7025-7034.

10 Liang H, Xu C, Pan Z, Zhang Y, Xu Z, Chen Y, Li T, Li X, Liu Y, Huangfu L, Lu Y, Zhang Z, Yang B, Gitau S, Shan H, Du Z: The antifibrotic effects and mechanisms of microRNA-26a action in idiopathic pulmonary fibrosis. Mol Ther 2014;22:1122-1133.

11 Tao A, Song J, Lan T, Xu X, Kvietys P, Kao R, Martin C, Rui T: Cardiomyocyte-fibroblast interaction contributes to diabetic cardiomyopathy in mice: Role of HMGB1/TLR4/IL-33 axis. Biochim Biophys Acta 2015;185:22075-22085.

12 Zhang Y, Huang XR, Wei LH, Chung AC, Yu CM, Lan HY: miR-29b as a therapeutic agent for angiotensin IIinduced cardiac fibrosis by targeting TGF- $\beta$ /Smad3 signaling. Mol Ther 2014;22:974-985.

13 He Y, Huang C, Lin X, Li J: MicroRNA-29 family, a crucial therapeutic target for fibrosis diseases. Biochimie 2013;95:1355-1359.

14 Melo SF, Fernandes T, Baraúna VG, Matos KC, Santos AA, Tucci PJ, Oliveira EM: Expression of MicroRNA-29 and Collagen in Cardiac Muscle after Swimming Training in Myocardial-Infarcted Rats. Cell Physiol Biochem 2014;33:657-669.

15 Zhao X, Wang K, Liao Y, Zeng Q, Li Y, Hu F, Liu Y, Meng K, Qian C, Zhang Q, Guan H, Feng K, Zhou Y, Du Y, Chen Z: MicroRNA-101a inhibits cardiac fibrosis induced by hypoxia via targeting TGFßRI on cardiac fibroblasts. Cell Physiol Biochem 2015;35:213-226. 


\section{Cellular Physiology Cell Physiol Biochem 2016;40:1345-1353 \begin{tabular}{l|l|l}
\hline DOI: 10.1159/000453187 & $\begin{array}{l}\text { C) 2016 The Author(s). Published by S. Karger AG, Basel } \\
\text { www.karger.com/cpb }\end{array}$ \\
\hline
\end{tabular}}

Hong et al.: MiR-22 Suppress Cardiac Fibrogenesis by Targeting TGFßRI

16 Yin K, Zhao L, Feng D, Ma W, Liu Y, Wang Y, Liang J, Yang F, Bi C, Chen H, Li X, Lu Y, Cai B: Resveratrol Attenuated Low Ambient Temperature-Induced Myocardial Hypertrophy via Inhibiting Cardiomyocyte Apoptosis. Cell Physiol Biochem 2015;35:2451-2462.

17 Cavarretta E, Condorelli G: miR-21 and cardiac fibrosis: another brick in the wall? Eur Heart J 2015;36:2139-2141.

18 Dong S, Ma W, Hao B, Hu F, Yan L, Yan X, Wang Y, Chen Z, Wang Z: microRNA-21 promotes cardiac fibrosis and development of heart failure with preserved left ventricular ejection fraction by up-regulating Bcl-2. Int J Clin Exp Pathol 2014;7:565-574.

19 Bauersachs J: miR-21: a central regulator of fibrosis not only in the broken heart. Cardiovasc Res 2012;96:227-229; discussion 230-223.

20 Thum T, Gross C, Fiedler J, Fischer T, Kissler S, Bussen M, Galuppo P, Just S, Rottbauer W, Frantz S, Castoldi M, Soutschek J, Koteliansky V, Rosenwald A, Basson MA, Licht JD, Pena JT, Rouhanifard SH, Muckenthaler MU, Tuschl T, Martin G.R, Bauersachs J, Engelhardt S: MicroRNA-21 contributes to myocardial disease by stimulating MAP kinase signalling in fibroblasts. Nature 2008;456:980-984.

21 Duisters RF, Tijsen AJ, Schroen B, Leenders JJ, Lentink V, van der Made I, Herias V, van Leeuwen RE, Schellings MW, Barenbrug P, Maessen JG, Heymans S, Pinto YM, Creemers EE: miR-133 and miR-30 regulate connective tissue growth factor: implications for a role of microRNAs in myocardial matrix remodeling. Circ Res 2009;104:170-178, 176p following 178.

22 Kaur K, Vig S, Srivastava R, Mishra A, Singh VP, Srivastava AK, Datta M: Elevated Hepatic miR-22-3p Expression Impairs Gluconeogenesis by Silencing the Wnt-Responsive Transcription Factor Tcf 7. Diabetes 2015;64:3659-3669.

23 Huang ZP, Wang DZ: miR-22 in cardiac remodeling and disease. Trends Cardiovasc Med 2014;24:267-272.

24 Ahmad HM, Muiwo P, Ramachandran SS, Pandey P, Gupta YK, Kumar L, Kulshreshtha R, Bhattacharya A: miR-22 regulates expression of oncogenic neuro-epithelial transforming gene 1 , NET1. FEBS J 2014;28:13904-13919.

25 Huang ZP, Chen J, Seok HY, Zhang Z, Kataoka M, Hu X, Wang DZ: MicroRNA-22 regulates cardiac hypertrophy and remodeling in response to stress. Circ Res 2013;112:1234-1243.

26 Gurha P, Abreu-Goodger C, Wang T, Ramirez MO, Drumond AL, van Dongen S, Chen Y, Bartonicek N, Enright AJ, Lee B, Kelm RJ Jr, Reddy AK, Taffet GE, Bradley A, Wehrens XH, Entman ML, Rodriguez A: Targeted deletion of microRNA-22 promotes stress-induced cardiac dilation and contractile dysfunction. Circulation 2012;125:2751-2761.

27 Gurha P, Wang T, Larimore AH, Sassi Y, Abreu-Goodger C, Ramirez MO, Reddy AK, Engelhardt S, Taffet GE, Wehrens XH, Entman ML, Rodriguez A: microRNA-22 promotes heart failure through coordinate suppression of PPAR/ERR-nuclear hormone receptor transcription. PLoS One 2013;8:e75882.

28 Leask A: TGFbeta, cardiac fibroblasts, and the fibrotic response. Cardiovasc Res 2007;74:207-212.

29 Gabbiani G: The myofibroblast in wound healing and fibrocontractive diseases. J Pathol 2003;200:500-503.

30 Eckes B, Zigrino P, Kessler D, Holtkötter O, Shephard P, Mauch C, Krieg T: Fibroblast-matrix interactions in wound healing and fibrosis. Matrix Biol 2000;19:325-332.

31 Tan SM, Zhang Y, Connelly KA, Gilbert RE, Kelly DJ: Targeted inhibition of activin receptor-like kinase 5 signaling attenuates cardiac dysfunction following myocardial infarction. Am J Physiol Heart Circ Physiol 2010;298:H1415-1425. 